\section{Kidney Blood Pressure Research}

\title{
Proteinuria as a Risk Factor for Decline in Residual Renal Function in Non-Diabetic Peritoneal Dialysis Patients
}

\author{
Seok Hui Kang Kyu Hyang Cho Jong Won Park Kyung Woo Yoon \\ Jun Young Do \\ Division of Nephrology, Department of Internal Medicine, Yeungnam University Hospital, Daegu, Korea
}

\section{Key Words}

Peritoneal dialysis • Residual Renal Function • Proteinuria

\begin{abstract}
Background: Preservation of residual renal function (RRF) is a major issue for patients on peritoneal dialysis (PD). Whether proteinuria is associated with a decline in RRF in patients on PD remains unclear. Patients and Methods: We reviewed the medical records at the Yeungnam University Hospital in Korea and identified patients who started PD between June 1995 and August 2011. A total of 147 non-diabetic patients were enrolled in the study. The patients were divided into 3 groups with respect to the tertile of initial proteinuria level: Low $(\mathrm{n}=49 ;<320 \mathrm{mg} /$ day), Middle $(\mathrm{n}=49 ; 320-822 \mathrm{mg} /$ day), and High groups $(\mathrm{n}=49 ;>822 \mathrm{mg} /$ day). Results: The mean patient age was $50.2 \pm 15.0$ years in the Low tertile, $50.2 \pm 15.4$ years in the Middle tertile, and $49.0 \pm 15.1$ years in the High tertile. Decline in RRF during follow-up period was greater in the High tertile than that in the other tertiles $(P=0.001)$. The proportion of patients with RRF $>50 \%$ of baseline at 24 months after the initiation of PD was $83 \%$ in the Low tertile, $66 \%$ in the Middle tertile, and $40 \%$ in the High tertile $(P<0.001)$. The multivariate analysis after adjusting for initial RRF, age, gender, underlying disease of end-stage renal disease except diabetes mellitus, PD modality, use of icodextrin, PD-associated peritonitis, and tertile of the initial proteinuria level revealed that High tertile of the initial proteinuria level was associated with a decline in RRF (hazard ratios: 2.442 for the Middle tertile, $P=0.007 ; 3.713$ for the Low tertile, $P<0.001$ ). Conclusion: The present study demonstrates that proteinuria may be is associated with a rapid decline in RRF in non-diabetic patients on PD, although the potential role of additional factors should be further investigated in prospective studies.
\end{abstract}




\section{Kidney Blood Pressure Research}

\section{Introduction}

Peritoneal dialysis (PD) is an established renal replacement therapy for patients with end-stage renal disease (ESRD). Preservation of residual renal function (RRF) is a major issue for patients on PD. RRF is associated with several functions, including calcium-phosphate balance, nutrition, inflammation, removal of uremic toxins, and improved blood pressure control [1-5]. Finally, preservation of RRF is associated with better survival rate and quality of life in patients on PD. The Kidney Disease Outcomes Quality Initiative (K/DOQI) guideline recommends the use of renin-angiotensin system (RAS) blockade, prevention of insults to RRF or volume depletion, and monitoring of RRF [5].

Proteinuria has been associated with increasing glomerular injury. In addition, proteinuria plays a role in tubular inflammation and fibrosis [6]. Thus, proteinuria leads to deterioration of renal function in patients with chronic kidney disease (CKD). There have been many reports regarding the effects of proteinuria on renal function in patients with nondialysis CKD [6-10]. At the time of PD initiation, the amount of proteinuria differs according to the underlying cause of ESRD or the RRF. There have been few reports concerning the effects of proteinuria on RRF in patients receiving dialysis. Using univariate analysis, Singhal et al. showed that high proteinuria is associated with faster decline of RRF [11]. However, whether proteinuria is associated with a decline in RRF in patients on PD remains unclear; hence, in this study, we aimed to address this.

\section{Patients and Methods}

\section{Selection of patients}

We reviewed the medical records at the Yeungnam University Hospital in Korea and identified 547 Asian patients (age > 18 years) who started PD between June 1995 and August 2011. We excluded 268 patients who had diabetes mellitus (DM) as the underlying cause of ESRD, 47 patients with an initial urine output $<200 \mathrm{~mL} /$ day, and 85 patients with $<6$ months of follow-up. DM was defined as the use of insulin or oral hypoglycemic agents, or a fasting glucose of $\geq 126 \mathrm{mg} / \mathrm{dL}$ or a 2-h post-glucose challenge value of $\geq 200 \mathrm{mg} / \mathrm{dL}$. None of the patients were undergoing PD for protein-losing diseases such as multiple myeloma. A total of 147 patients were enrolled in the study. The patients were divided into 3 groups with respect to the tertile of the initial proteinuria level: Low ( $=49 ;<320 \mathrm{mg} /$ day), Middle ( $\mathrm{n}=49 ; 320-822 \mathrm{mg} /$ day), and High groups ( $\mathrm{n}=49 ;>822 \mathrm{mg} /$ day). This study was approved by the institutional review board of the Yeungnam University Hospital. The board waived the need for informed consent.

\section{Clinical information}

The clinical and laboratory data collected at the time of PD initiation included age, gender, underlying cause of ESRD, peritoneal equilibration test (PET), urine volume (mL/day), ultrafiltration volume (mL/ day), high sensitivity C-reactive protein level (hs-CRP; mg/dL), serum albumin level (g/dL), RRF (mL/ $\left.\mathrm{min} / 1.73 \mathrm{~m}^{2}\right)$, serum creatinine $(\mathrm{mg} / \mathrm{dL})$, weekly total creatinine clearance $\left(\mathrm{CrCl}\right.$; $\left.\mathrm{L} / \mathrm{wk} / 1.73 \mathrm{~m}^{2}\right)$, weekly $\mathrm{Kt} /$ Vurea, dialysis modality (automated PD), use of diuretics, and 24-hr proteinuria level (mg/day). Serum albumin, creatinine, and hs-CRP were measured with an Olympus AU5400 automatic chemical analyzer (bromocresol green for albumin and alkaline picrate Jaffé kinetic for creatinine). $\mathrm{CrCl}$ was calculated according to a previous study [12].

The following data were documented from patient records during the first 2 years: peritonitis, technical failure, serum creatinine, creatinine clearance, edema index, and the use of icodextrin, low glucose degradation product (GDP) dialysate, and RAS blockade. During the follow-up period, patients who received icodextrin or RAS blockade were defined as those treated for more than 6 months. The type of dialysate (high or low GDP) was defined as a dialysate that was received during $\geq 50 \%$ of the follow-up period. PDassociated peritonitis was defined as a symptom or sign (abdominal pain, fever, and/or turbid dialysate) combined with an effluent cell count with white blood cells found at more than $100 / \mathrm{uL}$, with at least $50 \%$ polymorphonuclear neutrophilic cells. In our center, patients with peritonitis are treated with cefazolin sodium and tobramycin sulfate as the first-line antibiotics. Technical failure was defined as catheter removal 


\section{Kidney Blood Pressure Research}

owing to catheter-associated infection and mechanical problems. The edema index was measured by multifrequency bioimpedance analysis (In-Body 4.0; Biospace, Seoul, Korea), with the subject in a standing position. This analysis was performed every 6 months with patients' consent. Measurements were taken after drainage of the dialysate. The edema index was defined as the ratio of extracellular fluid to total body fluid.

The laboratory parameters were measured every 6 months after the initiation of PD during the first 2 years. Patients were censored at the event of death, follow-up loss, transfer to HD, or kidney transplantation. A modified $4.25 \%$ PET was performed. The intra-abdominal fluid was drained, and PD fluid containing $4.25 \%$ glucose was infused intraperitoneally [13]. The creatinine level of the drained dialysate, 4 -h after the injection, was divided by the blood creatinine levels to obtain the D/P Cr ratio. High transporter was defined as a $\mathrm{D} / \mathrm{P} \mathrm{Cr}$ ratio of $>0.81$ [14]. The sodium ( $\mathrm{Na}$ ) levels in the drained dialysate, $1 \mathrm{~h}$ after injection, was divided by the blood Na levels to obtain the $\mathrm{D} / \mathrm{P} 1_{\mathrm{Na}}$ ratio. The weekly $K t / V$ urea was calculated on the basis of 24-h urine and dialysate as follows: weekly $K t / V$ urea $=7 \times\{[24$-h urine urea nitrogen content $(\mathrm{mg} / \mathrm{dL}) \times 24$-h urine volume $(\mathrm{L})]+[24-\mathrm{h}$ dialysate urea nitrogen content $(\mathrm{mg} / \mathrm{dL}) \times 24$-h drain volume $(\mathrm{L})]\} /[$ distribution volume of urea $(\mathrm{L}) \times$ serum urea nitrogen $(\mathrm{mg} / \mathrm{dL})]$ [15]. The distribution volume of urea was calculated with $V$, estimated from a previous study [16]. Inadequate dialysis was defined as a weekly $K t / V u r e a$ value of $<1.7$ in the K/DOQI guideline [5]. Proteinuria level (mg/day) and RRF were measured by using the 24-h urine collection. The RRF was calculated on the basis of the 24-h urine collection as follows: RRF $=0.5 \times$ [24-h urine creatinine content $(\mathrm{mg} / \mathrm{dL}) /$ serum creatinine $(\mathrm{mg} / \mathrm{dL})+24$-h urine urea nitrogen content $(\mathrm{mg} /$ $\mathrm{dL}$ )/serum urea nitrogen $(\mathrm{mg} / \mathrm{dL})] \times 1.73 /$ body surface area $\left(\mathrm{m}^{2}\right)$ [15]. Our center made efforts to reduce the error in RRF evaluation by educating the patients and by trend analysis of the monthly urine volume. If the clinician thought that the RRF evaluation was inappropriate, we repeated the 24-h urine collection. The slope of the RRF decline was determined using the least-square method $\left(\mathrm{mL} / \mathrm{min} / 6\right.$ months $\left./ 1.73 \mathrm{~m}^{2}\right)$ from the initiation of PD to the end-point of follow-up or the time of anuria. A significant decline in RRF was defined as a RRF loss of $>50 \%$ from baseline. This is a hypothetical cutoff for RRF decline. Some studies have used this as a criterion to indicate a significant decline in $\operatorname{RRF}[16,17]$. Anuria was defined as $<100 \mathrm{~mL} /$ day of urine volume.

\section{Statistical methods}

The data were analyzed using SPSS version 19 (SPSS, Chicago, IL, USA). Continuous data are represented as mean \pm SD; categorical variables are expressed as counts and percentages. Differences in continuous variables were compared using a $t$-test and one-way analysis of variance (ANOVA), and differences in categorical variables were compared using either Pearson's $\chi^{2}$ test or Fisher's exact test. One-way ANOVA were followed by a post hoc Tukey comparison. Multivariate analyses of covariance were used to determine the independent predictors of the slope of RRF. Survivals from $>50 \%$ loss of RRF or anuria were calculated with the life table and cox regression analyses. Survival curves were plotted using Life table method. $P$ values $<0.05$ were considered statistically significant.

\section{Results}

Clinical characteristics at the time of PD initiation and at 24 months after PD initiation

The mean patient age was $50.2 \pm 15.0$ years in the Low tertile $(n=49), 50.2 \pm 15.4$ years in the Middle tertile $(n=49)$, and $49.0 \pm 15.1$ years in the High tertile $(n=49)$. Male, automated PD, and use of icodextrin in the High tertile were greater than that in the Low and Middle tertile (Table 1). Decline in RRF during follow-up period was greater in the High tertile than that in the other tertiles $(P=0.001)$. Initial weekly $K t / V u r e a$ in the Low tertile was higher than that in the Middle tertile $(P=0.049)$. There was no significant difference in the number of patients received inadequate dialysis among the 3 tertiles $(P=0.143)$. The serum albumin levels were $3.68 \pm 0.50 \mathrm{~g} / \mathrm{dL}$ in the Low tertile, $3.76 \pm 0.49 \mathrm{~g} / \mathrm{dL}$ in the Middle tertile, and $3.62 \pm 0.47 \mathrm{~g} / \mathrm{dL}$ in the High tertile $(P=0.341$, coefficient of variation $=0.132)$. The hs-CRP levels were $0.44 \pm 0.81 \mathrm{mg} / \mathrm{dL}$ in the Low tertile, $0.59 \pm 1.12 \mathrm{mg} / \mathrm{dL}$ in the Middle tertile, and $0.76 \pm 1.22 \mathrm{mg} / \mathrm{dL}$ in the High tertile $(P=0.363$, coefficient of variation $=1.78)$. For RAS blockade in the Low tertile, angiotensin converting enzyme inhibitor (ACEI) was 


\section{Kidney Blood Pressure Research}

Table 1. Clinical characteristics according to the initial proteinuria level at the time of PD and at 24 months after PD initiation

\begin{tabular}{|c|c|c|c|c|}
\hline $\begin{array}{l}\text { Clinical characteristics } \\
\text { at PD initiation }\end{array}$ & $\begin{array}{c}\text { Low tertile } \\
(\mathrm{n}=49)\end{array}$ & $\begin{array}{l}\text { Middle tertile } \\
(\mathrm{n}=49)\end{array}$ & $\begin{array}{l}\text { High tertile } \\
(\mathrm{n}=49)\end{array}$ & $P$ value* \\
\hline Age (years) & $50.2 \pm 15.0$ & $50.2 \pm 15.4$ & $49.0 \pm 15.1$ & 0.901 \\
\hline Gender (male) & $20(40.8 \%)$ & $21(42.9 \%)$ & $36(73.5 \%)$ & 0.001 \\
\hline Underlying disease of ESRD & & & & 0.141 \\
\hline Hypertension & $31(63.2 \%)$ & $29(59.2 \%)$ & $23(46.9 \%)$ & \\
\hline Glomerulonephritis & $4(8.2 \%)$ & $14(28.6 \%)$ & $15(30.6 \%)$ & \\
\hline Polycystic kidney disease & $3(6.1 \%)$ & $3(6.1 \%)$ & $1(2.0 \%)$ & \\
\hline Others $\#$ & $11(22.5 \%)$ & $3(6.1 \%)$ & $10(20.5 \%)$ & \\
\hline Dialysis modality (APD) & $1(2.0 \%)$ & $4(8.2 \%)$ & $10(20.4 \%)$ & 0.009 \\
\hline Use of diuretics & $36(73.5 \%)$ & $33(67.3 \%)$ & $34(69.4 \%)$ & 0.797 \\
\hline Use of icodextrin & $5(10.2 \%)$ & $13(26.5 \%)$ & $25(51.0 \%)$ & $<0.001$ \\
\hline Use of RAS blockade & $42(85.7 \%)$ & $38(77.6 \%)$ & $40(81.6 \%)$ & 0.580 \\
\hline hs-CRP level (mg/dL) & $0.44 \pm 0.81$ & $0.59 \pm 1.12$ & $0.76 \pm 1.22$ & 0.363 \\
\hline \multicolumn{5}{|l|}{ PET } \\
\hline $\mathrm{D} / \mathrm{P} 1_{\mathrm{Na}}$ & $0.89 \pm 0.02$ & $0.88 \pm 0.06$ & $0.89 \pm 0.05$ & 0.883 \\
\hline High transporter & $5(10.2 \%)$ & $4(8.2 \%)$ & $5(10.2 \%)$ & 0.924 \\
\hline Ultrafiltration volume (mL/day) & $400 \pm 655$ & $394 \pm 571$ & $297 \pm 588$ & 0.644 \\
\hline Urine volume (mL/day) & $1027 \pm 706^{\mathrm{a}, \mathrm{b}}$ & $883 \pm 430^{\mathrm{a}}$ & $1263 \pm 601^{b}$ & 0.007 \\
\hline Serum creatinine $(\mathrm{mg} / \mathrm{dL})$ & $7.23 \pm 2.27$ & $7.64 \pm 2.72$ & $8.17 \pm 2.75$ & 0.203 \\
\hline $\mathrm{CrCl}\left(\mathrm{L} / \mathrm{wk} / 1.73 \mathrm{~m}^{2}\right)$ & $90.1 \pm 33.3$ & $87.8 \pm 31.1$ & $96.6 \pm 27.8$ & 0.345 \\
\hline Weekly $\mathrm{Kt} /$ Vurea & $2.55 \pm 0.70^{\mathrm{a}}$ & $2.20 \pm 0.60^{\mathrm{b}}$ & $2.37 \pm 0.72^{\mathrm{a}, \mathrm{b}}$ & 0.049 \\
\hline Inadequate dialysis & $4(8.2 \%)$ & $11(22.4 \%)$ & $9(18.4 \%)$ & 0.143 \\
\hline Serum albumin level $(\mathrm{g} / \mathrm{dL})$ & $3.68 \pm 0.50$ & $3.76 \pm 0.49$ & $3.62 \pm 0.47$ & 0.341 \\
\hline Edema index & $0.352 \pm 0.017$ & $0.354 \pm 0.020$ & $0.356 \pm 0.018$ & 0.472 \\
\hline $\mathrm{RRF}\left(\mathrm{mL} / \mathrm{min} / 1.73 \mathrm{~m}^{2}\right)$ & $3.47 \pm 2.47$ & $3.40 \pm 2.27$ & $4.37 \pm 2.21$ & 0.074 \\
\hline Proteinuria level (mg/day) & $135 \pm 72^{\mathrm{a}}$ & $572 \pm 133^{a}$ & $2595 \pm 2492^{b}$ & $<0.001$ \\
\hline At 24 months after PD initiation & $(n=42)$ & $(n=36)$ & $(n=37)$ & \\
\hline Ultrafiltration volume (mL/day) & $614 \pm 442^{\mathrm{a}}$ & $781 \pm 622^{a, b}$ & $990 \pm 609 \mathrm{~b}$ & 0.024 \\
\hline Urine volume (mL/day) & $933 \pm 503^{a}$ & $720 \pm 507 a, b$ & $485 \pm 532^{b}$ & 0.002 \\
\hline Serum creatinine $(\mathrm{mg} / \mathrm{dL})$ & $8.14 \pm 2.70^{\mathrm{a}}$ & $9.94 \pm 2.87 \mathrm{~b}$ & $12.8 \pm 3.68^{c}$ & $<0.001$ \\
\hline $\mathrm{CrCl}\left(\mathrm{L} / \mathrm{wk} / 1.73 \mathrm{~m}^{2}\right)$ & $85.0 \pm 35.4^{\mathrm{a}}$ & $74.9 \pm 31.7^{a}$ & $58.3 \pm 14.9^{b}$ & 0.001 \\
\hline Weekly $\mathrm{Kt} /$ Vurea & $2.34 \pm 0.66^{\mathrm{a}}$ & $2.07 \pm 0.39 \mathrm{a}$ & $1.87 \pm 0.33^{b}$ & 0.001 \\
\hline Inadequate dialysis & $3(8.3 \%)$ & $8(24.2 \%)$ & $9(27.3 \%)$ & 0.047 \\
\hline Edema index & $0.349 \pm 0.015$ & $0.348 \pm 0.019$ & $0.353 \pm 0.015$ & 0.339 \\
\hline $\mathrm{RRF}\left(\mathrm{mL} / \mathrm{min} / 1.73 \mathrm{~m}^{2}\right)$ & $4.01 \pm 4.24 \mathrm{a}$ & $2.47 \pm 2.65^{\mathrm{a}}$ & $1.19 \pm 1.43^{\mathrm{b}}$ & 0.001 \\
\hline Proteinuria level (mg/day) & $317 \pm 300$ & $395 \pm 373$ & $545 \pm 821$ & 0.236 \\
\hline Delta proteinuria (mg/2 years) & $184 \pm 311$ & $-178 \pm 376$ & $-1786 \pm 2469$ & $<0.001$ \\
\hline PD-associated peritonitis (presence) & $14(33.3 \%)$ & $15(41.7 \%)$ & $15(40.5 \%)$ & 0.708 \\
\hline \multicolumn{5}{|c|}{$\begin{array}{l}\text { Data are expressed as numbers (percentages) for the categorical variables and as mean } \pm \text { standard } \\
\text { deviation for the continuous variables. *Statistical significance was tested by one-way analysis of variance } \\
\text { for the continuous variables and Pearson } \chi^{2} \text { test or Fisher exact test for the categorical variables. Different } \\
\text { superscripts (a,b,c) indicate significant differences from each other based on post hoc Tukey comparison. } \\
\text { "Low tertile: unknown cause in } 6 \text { patients, postoperative acute kidney injury in } 2 \text { patients, eclampsia in } 1 \\
\text { patient, lupus nephritis in } 1 \text { patient, and gout in } 1 \text { patient; Middle tertile: unknown cause in } 3 \text { patients; High } \\
\text { tertile: unknown cause in } 6 \text { patients, renal tuberculosis in } 2 \text { patients, nephrectomy in } 1 \text { patient, and drug- } \\
\text { induced nephropathy in } 1 \text { patient. PD, peritoneal dialysis; ESRD, end-stage renal disease; APD, automated } \\
\text { peritoneal dialysis; RAS, renin-angiotensin system; hs-CRP, high sensitivity C-reactive protein; PET, } \\
\text { peritoneal equilibration test; D/P1Na, dialysate to plasma sodium ratio at } 1 \mathrm{~h} \text {; CrCl, weekly total creatinine } \\
\text { clearance; RRF, residual renal function }\end{array}$} \\
\hline
\end{tabular}

given to 7 patients, angiotensin receptor blocker (ARB) to 32 patients, and both to 3 patients. In the Middle tertile, 11 patients received ACEI, 25 patients received ARB, and 2 patients received both. In the High tertile, 5 patients received ACEI, 33 patients received ARB, and 2 patients received both. There was no significant difference in the underlying cause of ESRD, use of diuretics, use of RAS blockade, $\mathrm{D} / \mathrm{P} 1_{\mathrm{Na}^{\prime}}$ ultrafiltration volume, and $\mathrm{CrCl}$ at the time of PD initiation. 
One hundred fifteen of 147 patients were followed for 24 months after PD initiation. Patients were censored owing to follow-up loss (19 patients), death (6 patients), transfer to kidney transplantation ( 4 patients), and transfer to HD (3 patients). Forty-two patients in the Low tertile, 36 patients in the Middle tertile, and 37 patients in the High tertile completed 24 months of follow-up after the time of PD initiation. At 24 months after PD initiation, the urine volume and RRF in the Low tertile were higher than those in the High tertile $(P=0.002$ for urine volume and $P=0.001$ for RRF). The ultrafiltration volume in the Low tertile was less than that in the High tertile $(P=0.024)$. Serum creatinine was significantly higher in the High tertile than in the other tertiles $(P=0.001)$. Weekly $K t / V$ urea and $\mathrm{CrCl}$ in the Low tertile were higher than those in the other tertiles $(P=0.001)$. There were more patients receiving inadequate dialysis in the High tertile than in the other tertiles $(P=0.047)$. There was no significant difference in proteinuria and PD-associated peritonitis at 24 months after PD initiation. Technical failure during the follow-up period occurred in one patient in each tertile.

The proteinuria levels in High tertile significantly decreased during follow-up (Figure 1): $2595 \pm 2492 \mathrm{mg} /$ day at PD initiation and $545 \pm 821 \mathrm{mg} /$ day at 24 months $(P<0.001)$. In the Middle tertile, the level was $572 \pm 133 \mathrm{mg} /$ day at PD initiation and $395 \pm 373 \mathrm{mg} /$ day at 24 months $(P=0.004)$. In contrast, the proteinuria level in the Low tertile increased from $135 \pm 72 \mathrm{mg} /$ day to $317 \pm 300 \mathrm{mg} /$ day $(P=0.001)$.

\section{Factors affecting RRF decline}

The proportion of patients with $\mathrm{RRF}>50 \%$ of baseline at 24 months after the initiation of PD was $83 \%$ in the Low tertile, $66 \%$ in the Middle tertile, and $40 \%$ in the High tertile $(P<0.001)$ (Figure 2). To identify the variables predicting a $>50 \%$ loss of RRF, the clinical and laboratory test results were analyzed using univariate and multivariate analyses (Table 2 ). The univariate analysis revealed that glomerulonephritis as an underlying disease of ESRD, the use of icodextrin, and being in the High tertile of the initial proteinuria level were associated with a $>50 \%$ loss of RRF. The multivariate analysis after adjusting for initial RRF, age, gender, underlying disease of ESRD, PD modality, use of icodextrin, PD-associated peritonitis, and tertile of the initial proteinuria level revealed that being in the High tertile of the initial proteinuria level was associated with a $>50 \%$ loss of RRF. The hazard ratios of the High tertile of proteinuria were 2.442 (confidence interval, 1.283-4.646; $P=0.007$ ) for the middle tertile and 3.713 (confidence interval, 1.782-7.738; $P<0.001$ ) for the low tertile. The anuria-free survival rate at 24 months was higher in the Low tertile than in High tertile $(P=0.039 ; 94 \%, 93 \%$, and $73 \%$ in the Low, Middle, and High tertiles, respectively) (Figure 3).

The univariate analysis revealed that the underlying disease of ESRD and the tertile of initial proteinuria were associated with the slope of RRF during the follow-up period (Table 3 ). Age, gender, GDP solution, use of RAS blockade, use of diuretics, use of icodextrin, PD modality, and PD-associated peritonitis were not associated with the slope of RRF during the follow-up period. The multivariate analysis after adjusting for initial RRF, age, gender, underlying disease of ESRD, PD modality, use of icodextrin, PD-associated peritonitis, and tertile of the initial proteinuria revealed that the High tertile of initial proteinuria was associated with a steep slope of RRF during follow-up.

\section{Discussion}

Proteinuria is a result of CKD, and a risk factor for the progression of CKD. Proteinuria is associated with progressive injury through multiple pathways, including induction of tubular chemokine expression and complement activation that lead to inflammatory cell (e.g., macrophage) infiltration [6]. Proteinuria in CKD is associated with a decrease in the glomerular filtration rate and an increase in cardiovascular mortality [10]. The present study shows that an initial High tertile of proteinuria is an independent risk factor for the 


\section{Kidney Blood Pressure Research}

Table 2. Factors predicting a $>50 \%$ loss of residual renal function during follow-up

\begin{tabular}{lcccc}
\hline Characteristics & Univariate & Multivariate* \\
& HR (CI) & $P$ value & HR (CI) & $P$ value \\
\hline Age ( $\geq$ 65 years) & $1.034(0.549-1.947)$ & 0.917 & $1.061(0.544-2.071)$ & 0.862 \\
Gender (female) & $0.709(0.423-1.189)$ & 0.192 & $0.833(0.467-1.487)$ & 0.537 \\
Underlying disease of ESRD (GN) & $1.789(1.028-3.114)$ & 0.040 & $1.409(0.772-2.571)$ & 0.264 \\
PD modality (APD) & $1.647(0.746-3.637)$ & 0.217 & $1.125(0.451-2.807)$ & 0.800 \\
GDP solution (high) & $0.777(0.463-1.304)$ & 0.339 & & \\
Use of RAS blockade & $1.363(0.671-2.768)$ & 0.392 & & \\
Use of diuretics & $1.427(0.843-2.413)$ & 0.185 & & \\
Use of icodextrin & $2.163(1.294-3.617)$ & 0.003 & $1.205(0.666-2.180)$ & 0.537 \\
PD-associated peritonitis & $1.563(0.941-2.596)$ & 0.085 & $1.492(0.879-2.532)$ & 0.138 \\
Initial proteinuria level (reference: low tertile & & & \\
$\quad$ Middle tertile & $1.776(0.831-3.794)$ & 0.138 & $1.521(0.700-3.302)$ & 0.289 \\
High tertile & $4.108(2.061-8.187)$ & $<0.001$ & $3.713(1.782-7.738)$ & $<0.001$ \\
\hline
\end{tabular}

*The covariates were initial RRF, age, gender, underlying disease of ESRD, PD modality, use of icodextrin, PD-associated peritonitis, and tertile of the initial proteinuria level. HR, hazard ratio; CI, confidence interval; ESRD, end-stage renal disease; GN, non-glomerulonephritis; PD, peritoneal dialysis; APD, automated peritoneal dialysis; GDP, glucose degradation products; RAS, renin-angiotensin system

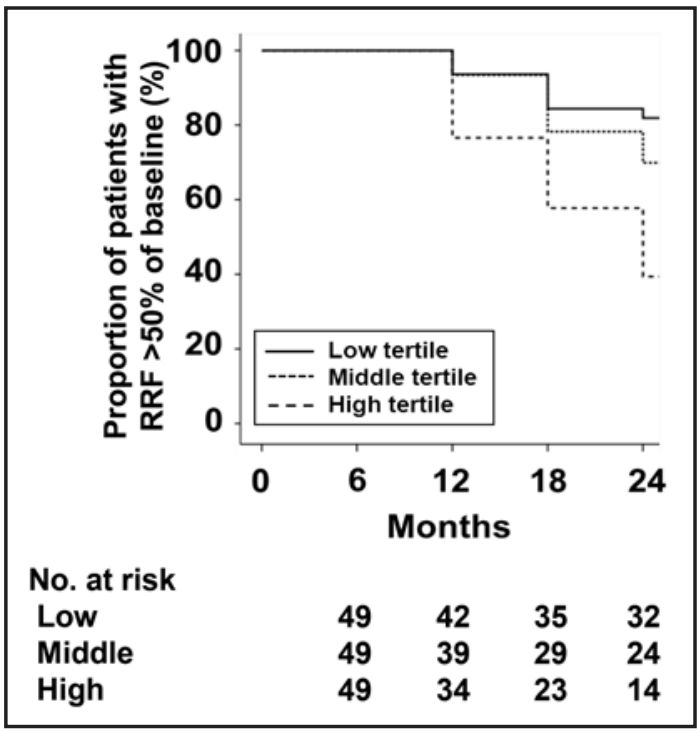

Fig. 1. Changes in proteinuria levels after PD initiation according to tertiles of proteinuria. Data are as follows (in $\mathrm{mg} /$ day): at PD initiation, $135 \pm 72$ for the Low tertile, $572 \pm 133$ for the Middle tertile, $2595 \pm 2492$ for the High tertile; at 6 months, $366 \pm$ 365 for the Low tertile, $423 \pm 378$ for the Middle tertile, $1086 \pm 1339$ for the High tertile; at 12 months, $357 \pm 336$ for the Low tertile, $345 \pm 234$ for the Middle tertile, $1118 \pm 1964$ for the High tertile; at 18 months, $394 \pm 430$ for the Low tertile, $321 \pm 296$ for the Middle tertile, $627 \pm 1038$ for the High tertile; at 24 months, $317 \pm 300$ for the Low tertile, $395 \pm 373$ for the Middle tertile, $545 \pm 821$ for the High tertile; ${ }^{*} \mathrm{P}<0.001$ vs. 24 months, \#P=0.004 vs. 24 months, and ${ }^{\dagger} \mathrm{P}=0.001$ vs. 24 months).

proteinuria and the decline in RRF on multivariate analysis. DM is a well-known nonmodifiable risk factor for the decline in RRF in patients on PD. When divided into groups
Fig. 2. Proportion of patients with residual renal function $>50 \%$ of baseline according to the tertile of initial proteinuria level tertile (24 months, $83 \%$ for the Low tertile, $66.0 \%$ for the Middle tertile, and $40.0 \%$ for the High tertile; $\mathrm{P}<0.001$ ).

rapid decline in RRF in non-diabetic patients on PD.

Singhal et al. showed that higher proteinuria is associated with faster decline on univariate analysis only and not on multivariate analysis [11]. In their study, high proteinuria was associated with a high incidence of DM, which may be associated with the lack of a relationship between 


\section{Kidney \\ Blood Pressure Research}

Table 3. Factors associated with the slope of RRF $\left(\mathrm{mL} / \mathrm{min} / 6 \mathrm{months} / 1.73 \mathrm{~m}^{2}\right)$ after the time of PD initiation

\begin{tabular}{|c|c|c|c|c|c|}
\hline \multirow{2}{*}{ Characteristics } & & \multicolumn{2}{|c|}{ Univariate } & \multicolumn{2}{|c|}{ Multivariate } \\
\hline & & Mean \pm SE & $P$ value* & Mean \pm SE & $P$ value* \\
\hline \multirow[t]{2}{*}{ Age } & $<65$ years & $-0.45 \pm 0.12$ & 0.131 & $-0.62 \pm 0.09$ & 0.208 \\
\hline & $\geq 65$ years & $-0.08 \pm 0.17$ & & $-0.32 \pm 0.22$ & \\
\hline \multirow[t]{2}{*}{ Gender } & Male & $-0.36 \pm 0.16$ & 0.939 & $-0.62 \pm 0.12$ & 0.586 \\
\hline & Female & $-0.38 \pm 0.12$ & & $-0.52 \pm 0.13$ & \\
\hline \multirow[t]{2}{*}{ Underlying disease of ESRD } & GN & $-0.73 \pm 0.19$ & 0.048 & $-0.68 \pm 0.19$ & 0.531 \\
\hline & Non-GN & $-0.26 \pm 0.12$ & & $-0.54 \pm 0.10$ & \\
\hline \multirow{2}{*}{ GDP solution } & Low & $-0.37 \pm 0.14$ & 0.965 & - & - \\
\hline & High & $-0.36 \pm 0.14$ & & - & \\
\hline \multirow[t]{2}{*}{ Use of RAS blockade } & Yes & $-0.35 \pm 0.21$ & 0.703 & - & - \\
\hline & No & $-0.45 \pm 0.11$ & & - & \\
\hline \multirow[t]{2}{*}{ Use of diuretics } & Yes & $-0.31 \pm 0.12$ & 0.362 & - & - \\
\hline & No & $-0.51 \pm 0.19$ & & - & \\
\hline \multirow[t]{2}{*}{ Dialysis modality } & CAPD & $-0.41 \pm 0.09$ & 0.466 & $-0.55 \pm 0.09$ & 0.443 \\
\hline & APD & $-0.08 \pm 0.65$ & & $-0.91 \pm 0.45$ & \\
\hline \multirow{2}{*}{ Use of icodextrin } & Yes & $-0.37 \pm 0.14$ & 0.976 & $-0.59 \pm 0.10$ & 0.681 \\
\hline & No & $-0.37 \pm 0.13$ & & $-0.51 \pm 0.17$ & \\
\hline \multirow[t]{2}{*}{ PD-associated peritonitis } & Presence & $-0.28 \pm 0.15$ & 0.514 & $-0.57 \pm 0.14$ & 0.995 \\
\hline & Absence & $-0.42 \pm 0.13$ & & $-0.57 \pm 0.11$ & \\
\hline \multirow[t]{3}{*}{ Initial proteinuria tertile } & Low & $-0.41 \pm 0.09$ & 0.040 & $-0.48 \pm 0.14$ & 0.022 \\
\hline & Middle & $-0.65 \pm 0.17$ & & $-0.37 \pm 0.14$ & \\
\hline & High & $-0.97 \pm 0.09$ & & $-1.00 \pm 0.18$ & \\
\hline \multicolumn{6}{|c|}{$\begin{array}{l}\text { *Univariate analysis was tested using t-test or one-way analysis of variance and multivariate analysis was } \\
\text { evaluated using analysis of covariance; the covariance was initial RRF, age, gender, underlying disease of } \\
\text { ESRD, dialysis modality, use of icodextrin, PD-associated peritonitis, and initial proteinuria tertile. RRF, } \\
\text { residual renal function; PD, peritoneal dialysis; SE, standard error; ESRD, end-stage renal disease; GN, } \\
\text { glomerulonephritis; GDP, glucose degradation products; RAS, renin-angiotensin system; CAPD, continuous } \\
\text { ambulatory peritoneal dialysis; APD, automated peritoneal dialysis }\end{array}$} \\
\hline
\end{tabular}

Fig. 3. Anuria-free survival curve according to the tertile of initial proteinuria level $(24$ months anuria-free survival rate: $94 \%$ for the Low tertile, $93 \%$ for the Middle tertile, and $73 \%$ for the High tertile; $\mathrm{P}=0.039$ for Low vs High tertile).

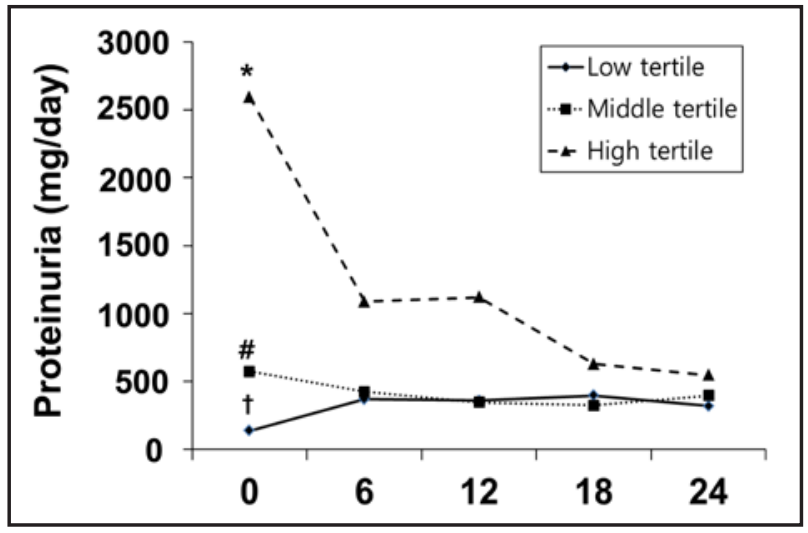

according to the proteinuria level, most patients with a high proteinuria were found to have DM. From our data, the ranges of proteinuria level in non-DM patients were $40-317 \mathrm{mg} / \mathrm{day}$ in the Low tertile, 318-822 mg/day in the Middle tertile, and 823-12,768 mg/day in the High tertile. The ranges in DM patients were 75-849 mg/day in the low tertile, 850-2370 $\mathrm{mg}$ /day in the middle tertile, and 2371-24,000 mg/day in the high tertile (data not shown). These findings revealed that most DM patients would be included in the middle or high tertiles, and this would result in an imbalanced inclusion. In addition, other vasculopathies or comorbidities combined with DM may be associated with decline in RRF. These factors would be difficult to express objectively and enter into a multivariate analysis in a retrospective study. Therefore, DM patients were excluded in the present study.

Jansen et al. showed that baseline proteinuria was associated with a rapid decline in RRF after 6 months of the start of dialysis; however, they did not perform multivariate analysis [18]. Although the previous two studies evaluated the predictors of decline in 


\section{Kidney Blood Pressure Research}

RRF in patients on dialysis, they were limited by the absence of sufficient adjustment for other factors $[11,19]$. In addition, evaluation of the effects of proteinuria on RRF was not the primary purpose of these studies. We enrolled non-DM patients to evaluate the effect of proteinuria on RRF decline, and investigated the effects of proteinuria on RRF by using multivariate analysis after adjusting for variables. The present study did not have a control arm; the purpose of this study was to evaluate changes in clinical outcomes according to proteinuria. A dichromatic approach, such as including normal and abnormal groups, will be prone to false-positive results. Therefore, the patients were divided into three tertiles according to the level of proteinuria. The patients could be divided into three groups according to normal ( $<150 \mathrm{mg} /$ day), non-nephrotic range proteinuria (150-3500 mg/day), and nephrotic range proteinuria $(>3500 \mathrm{mg} /$ day). This study is a retrospective study with a small number of patients. Dividing the patients according to absolute ranges would result in their uneven distribution.

If proteinuria is associated with a decline in RRF, the possible therapeutic options for decreasing proteinuria should be discussed. RAS blockades such as angiotensin converting enzyme blocker or angiotensin receptor blocker are well-known therapy for decreasing proteinuria. Although previous studies showed that RAS blockade slows the decline in RRF in patients on PD, they did not show a significant decline in proteinuria [20, 21]. There may be several reasons for this: (1) a secondary decrease in proteinuria combined with a decline in RRF; (2) a different pathophysiology for proteinuria in patients on dialysis; and (3) association of proteinuria in patients on dialysis with glomerular injury rather than hemodynamic change [20,21]. Moreover, RAS blockade dose not exhibit a positive effect on RRF in patients on PD, as demonstrated by the results from a recent large cohort study [22]. Further investigations are required to determine the definite effect of RAS blockade on the decline in proteinuria in patients on PD.

The association between RRF and PD solutions remains controversial. Previous studies reported conflicting results regarding the effect of low GDP dialysate on RRF [23-30]. These studies have many limitations such as study design, high drop-out rate, statistical error, lack of data for peritoneal ultrafiltration, and low baseline RRF. Therefore, a definite conclusion for association between low GDP dialysate and RRF could not be made. Recently, a balANZ trial tried to overcome these limitations. This study concluded that low GDP dialysate was not associated with the decline in RRF, but may delay the onset of anuria [30]. The present study did not show an association between the 2 variables; the use of low GDP dialysate was defined as the main dialysate used during the follow-up period. Patients who maintained the same dialysate for the follow-up period should be included to evaluate the effect of low GDP dialysate in RRF decline.

In the present study, patients in the higher proteinuria tertile used automated PD or icodextrin more than those in the lower tertiles. Patients with high proteinuria are associated with poor edema control. This could be associated with higher use of automated PD and icodextrin in patients in the high proteinuria tertile. Some patients may be hypovolemic and have a repercussion on RRF, but initial urine volume in the High tertile group was greater than the ultrafiltration volume. There were no significant difference among the tertiles, but there was an increasing trend in the edema index as the tertile of proteinuria level increased Takatori et al. showed that urine volume significantly decreased in the earlier period in patients using icodextrin compared with those using glucose solution; however, there was no significant difference between the two groups [31]. They also suggest that superior ultrafiltration may reduce the RRF if the duration of dialysis therapy is $>2$ years. The present study did not conclusively establish whether the RRF decline in the High tertile of proteinuria is associated with high ultrafiltration due to icodextrin use, or whether the poor edema control in the High tertile of proteinuria necessitated the use of icodextrin. A faster RRF decline in automated PD patients has been suggested in previous studies [32, 33], but other studies found no such evidence [34,35]. In the present study, automated PD was not associated with a significant decline in RRF; however, the number of patients on automated PD was small. Therefore, prospective studies with a larger sample size are needed. 


\section{Kidney Blood Pressure Research}

Kidney Blood Press Res 2013;37:199-210

DOI: 10.1159/000350145

Publisnea onine: vviay 30, 2013

Kang/Cho/Park/Yoon/Do: Proteinuria in PD Patients

Proteinuria itself is considered nephrotoxic and may be associated with further increase in urine protein levels. The common final pathway is decline in renal function. Most heavily proteinuric patients on dialysis have minimal RRF compared with non-dialysis patients. The predominant effect of heavy proteinuria may be a decrease in RRF rather than a increase in proteinuria levels. Finally, a rapid decline in RRF is associated with a high incidence of poor edema control. The decrease in proteinuria was greater in the High tertile than in the other tertiles. There were no significant differences between the tertiles; however, the trend showed that, at 24 months after PD initiation, the edema index in the High tertile was higher than that in the other tertiles. However, in the Low tertile, proteinuria significantly increased during follow-up and the RRF decline was lower than in the other tertiles. These suggest that low-grade proteinuria may be progressive and has less effect on the decline in RRF, but heavy proteinuria may predominantly lead to decrease in RRF rather than a further increase in proteinuria, and may be associated with poor edema control.

The PD-associated peritonitis and the use of aminoglycosides have also been associated with a faster loss of RRF $[11,36]$. Recently, a large study showed that empiric treatment with aminoglycoside for peritonitis was not associated with the loss of RRF [37]. In our center, most patients with peritonitis are treated with cefazolin sodium and tobramycin sulfate as the first-line antibiotics. During the follow-up period, most patients experienced only one episode of peritonitis. Therefore, we used the dichromatic approach for PD-associated peritonitis. There was no statistical significance in this regard; multivariate analysis revealed a 1.563 hazard ratio for a $>50 \%$ loss of RRF $(P=0.085)$. In addition, serum albumin is an independent risk factor for the development of peritonitis in PD patients [38]. Proteinuria would be associated with hypoalbuminemia, and this may be associated with a high incidence of peritonitis and high technical failure. In the present study, technical failure during the follow-up period occurred in one patient in each tertile. There was no significant difference in serum albumin between the three tertiles and the technical failure rate was small. Further studies including more patients will be needed to evaluate the association between proteinuria and technical failure.

High-dose diuretics would help increase urine volume and control the volume status. However, these may have additional side effects such as ototoxicity. There were controversies about whether diuretics are associated with the preservation of RRF. There were two conflicting studies about the role of diuretics in RRF decline [39, 40]. In a randomized study, Medcalf et al. showed that there was a significant increase in urine volume during 1 year but diuretics had no effect on preserving the RRF [39]. In a retrospective study, Liao et al. showed that patients with a rapid decline in RRF used diuretics more often than those with a slow decline in RRF [40]. Although our results favor the former study, randomized studies considering volume status and urine volume would be needed to elucidate the effect of diuretics on the decline in RRF.

The initial $\mathrm{Kt} /$ Vurea and $\mathrm{CrCl}$ in the High tertile were not significantly different from those observed in the other tertiles. At 24 months after PD initiation, the decline in RRF and urine volume in the High tertile was greater than that in the other tertiles, although the decline in urine volume was accompanied by an increase in peritoneal ultrafiltration volume. At 24 months after PD initiation, weekly $\mathrm{Kt} / \mathrm{Vurea}$ and $\mathrm{CrCl}$ in the High tertile were lower than that in the other tertiles. In addition, the number of patients receiving inadequate dialysis in the High tertile was greater than that in the other tertiles. This result shows that RRF plays an important role in the maintenance of adequate dialysis. The rapid decline in RRF in the High tertile may be associated with a low dialysis dose and high serum creatinine levels.

The present study is a retrospective study with a small sample size and inherent limitations such as selection bias and immortal bias. Only 147 patients $(26.9 \%)$ of the total 547 incident PD patients were included in the study. Patients with $<6$ months of follow-up were excluded. Patients had to survive for $>6$ months to be included in the study. The time interval for an event (RRF $<50 \%$ of baseline or anuria) was 6 months. Kaplan-Meier analysis is the preferred method for data without a regular time interval for an event. However, the 


\section{Kidney \\ Blood Pressure Research}

actuarial or life table method is preferred for data with regular or long time intervals such as in the present study. Therefore, data such as the survival curve data and the number of atrisk patients were analyzed using the life table method. In addition, as a single-center study, we could not evaluate differences across ethnicities. Although proteinuria is associated with a rapid decline in RRF, we were unable to reveal if a decrease in proteinuria is associated with the preservation of RRF. Prospective randomized controlled studies will be needed to overcome these limitations.

\section{Conclusion}

The present study demonstrates that proteinuria may be associated with a rapid decline in RRF in non-diabetic patients on PD, although the potential role of additional factors should be further investigated in prospective studies.

\section{Conflict of Interests}

The authors declare that they have no competing interests.

\section{Abbreviations list}

PD (peritoneal dialysis); ESRD (end-stage renal disease); RRF (residual renal disease); K/DOQI (Kidney Disease Outcomes Quality Initiative); RAS (renin-angiotensin system); CKD (chronic kidney disease); DM (diabetes mellitus); PET (peritoneal equilibrium test); hsCRP (high sensitivity C-reactive protein); $\mathrm{CrCl}$ (weekly creatinine clearance); GDP (glucose degradation product); Na (sodium); ANOVA (analysis of variance); ACEI (angiotensin converting enzyme inhibitor); ARB (angiotensin receptor blocker).

\section{References}

1 Mistry CD, O’Donoghue DJ, Nelson S, Gokal R, Ballardie FW: Kinetics and clinical studies of beta 2-microglobulin in continuous ambulatory peritoneal dialysis: influence of renal and enhanced peritoneal clearances using glucose polymer. Nephrol Dial Transplant 1990;5:513-519.

-2 Menon MK, Naimark DM, Bargman JM, Vas SI, Oreopoulos DG: Long-term blood pressure control in a cohort of peritoneal dialysis patients and its association with residual renal function. Nephrol Dial Transplant 2001;16:2207-2213.

- Pecits-Filho R, Heimbürger O, Bárány P, Suliman M, Fehrman-Ekholm I, Lindholm B, Stenvinkel P: Associations between circulating inflammatory markers and residual renal function in CRF patients. Am J Kidney Dis 2003;41:1212-1218.

4 Wang AY, Woo J, Wang M, Sea MM, Sanderson JE, Lui SF, Li PK: Important differentiation of factors that predict outcome in peritoneal dialysis patients with different degrees of residual renal function. Nephrol Dial Transplant 2005;20:396-403.

5 Peritoneal Dialysis Adequacy 2006 Work Group: Clinical practice guidelines and clinical practice recommendations for peritoneal dialysis adequacy, update 2006. Am J Kidney Dis 2006;48:S98-S129.

6 Abbate M, Zoja C, Remuzzi G: How does proteinuria cause progressive renal damage? J Am Soc Nephrol 2006;17:2974-2984. 


\section{Kidney \\ Blood Pressure Research}

7 Peterson JC, Adler S, Burkart JM, Greene T, Hebert LA, Hunsicker LG, King AJ, Klahr S, Massry SG, Seifter JL: Blood pressure control, proteinuria, and the progression of renal disease. The Modification of Diet in Renal Disease Study. Ann Intern Med 1995;123:754-762.

8 Iseki K, Iseki C, Ikemiya Y, Fukiyama K: Risk of developing end-stage renal disease in a cohort of mass screening. Kidney Int 1996;49:800-805.

-9 Ruggenenti P, Perna A, Mosconi L, Matalone M, Pisoni R, Gaspari F, Remuzzi G: Proteinuria predicts endstage renal failure in non-diabetic chronic nephropathies. The "Gruppo Italiano di Studi Epidemiologici in Nefrologia" (GISEN). Kidney Int 1997;63:S54-S57.

10 Wen CP, Cheng TY, Tsai MK, Chang YC, Chang HT, Tsai SP, Chiang PH, Hsu CC, Sung PK, Hsu YH, Wen SF: Allcause mortality attributable to chronic kidney disease: a prospective cohort study based on 462,293 adults in Taiwan. Lancet 2008;371:2173-2182.

11 Singhal MK, Bhaskaran S, Vidgen E, Bargman JM, Vas SI, Oreopoulos DG: Rate of decline of residual renal function in patients on continuous peritoneal dialysis and factors affecting it. Perit Dial Int 2000;20:429. 438.

12 National Kidney Foundation: K/DOQI clinical practice guidelines for peritoneal dialysis adequacy update 200. Am J Kidney Dis 2001;37:S65-S136.

13 Mujais S, Nolph K, Gokal R, Blake P, Burkart J, Coles G, Kawaguchi Y, Kawanishi H, Korbet S, Krediet R, Lindholm B, Oreopoulos D, Rippe B, Selgas R: Evaluation and management of ultrafiltration problems in peritoneal dialysis. International Society for Peritoneal Dialysis Ad Hoc Committee on Ultrafiltration Management in Peritoneal Dialysis. Perit Dial Int 2000;20:S5-S21.

14 Blake PG: Adequacy of peritoneal dialysis and chronic peritoneal dialysis prescription. In: Daugirdas JT, Blake PG, Ing TS, editors. Handbook of dialysis. $4^{\text {th }}$ edn. Philadelphia: Lippincott Williams \& Wilkins, 2007;387-409.

15 Mujais S, Smit W: Ultrafiltration failure. In: Khanna R, Krediet RT, editors. Nolph and Gokal's Textbook of Peritoneal Dialysis. $3^{\text {rd }}$ edn. Missouri: Springer Science, 2009;505-522.

16 Tian SL, Tian XK, Han QF, Axelsson J, Wang T: Presence of peripheral arterial disease predicts loss of residual renal function in incident CAPD patients. Perit Dial Int 2012;32:67-72.

17 Cheng LT, Chen W, Tang W, Wang T: Does loss of residual renal function lead to malnutrition in peritoneal dialysis patients? Clin Nephrol 2006;66:192-201.

18 Watson PE, Watson IE, Bratt RD: Total body water volumes for adult males and females estimated from simple anthropometric measurements. Am J Clin Nutr 1980;33:27-39.

19 Jansen MA, Hart AA, Korevarr JC, Dekker FW, Boeschoten EW, Krediet RT, NECOSAD Study Group: Predictors of the rate of residual renal function in incident dialysis patients. Kidney Int 2002;62:10461053.

20 Li PK, Chow KM, Wong TY, Leung CB, Szeto CC: Effects of an angiotensin-converting enzyme inhibitor on residual renal function in patients receiving peritoneal dialysis. A randomized, controlled study. Ann Intern Med 2003;139:105-112.

-21 Suzuki H, Kanno Y, Sugahara S, Okada H, Nakamoto H: Effects of an angiotensin II receptor blocker, valsartan, on residual renal function in patients on CAPD. Am J Kidney Dis 2004;43:1056-1064.

-22 Kolesnyk I, Noordzij M, Dekker FW, Boeschoten EW, Krediet RT: Treatment with angiotensin II inhibitors and residual renal function in peritoneal dialysis patients. Perit Dial Int 2011;31:53-59.

-23 Williams JD, Topley N, Craig KJ, Mackenzie RK, Pischetsrieder M, Lage C, Passlick-Deetjen J, Euro Balance Trial Group: The Euro-Balance Trial: the effect of a new biocompatible peritoneal dialysis fluid (balance) on the peritoneal membrance. Kidney Int 2004;66:408-418.

-24 Szeto CC, Chow KM, Lam CW, Leung CB, Kwan BC, Chung KY, Law MC, Li PK: Clinical biocompatibility of a neutral peritoneal dialysis solution with minimal glucose-degradation products-1 year randomized control trial. Nephrol Dial Transplant 2007;22:552-559.

-25 Fan SL, Pile T, Punzalan S, Raftery MJ, Yaqoob MM: Randomized controlled study of biocompatible peritoneal dialysis solutions: effect on residual renal function. Kidney Int 2008;73:200-206.

26 Kim S, Oh J, Kim S, Chung W, Ahn C, Kim SG, Oh KH: Benefits of biocompatible PD fluid for preservation of residual renal function in incident CAPD patients: a 1-year study. Nephrol Dial Transplant 2009;24:28992908. 


\section{Kidney \\ Blood Pressure Research}

Kidney Blood Press Res 2013;37:199-210

DOI: 10.1159/000350145

Publisned onine: IVlay 30, 2013

(C) 2013 S. Karger AG, Basel

www.karger.com/kbr

Kang/Cho/Park/Yoon/Do: Proteinuria in PD Patients

-27 Haag-Weber M, Krämer R, Haake R, Islam MS, Prischl F, Haug U, Nabut JL, Deppisch R, behalf of the DIUREST Study Group: Low-GDP fluid (Gambrosol trio) attenuates decline of residual renal function in PD patients: a prospective randomized study. Nephrol Dial Transplant 2010;25:2288-2296.

28 Park SH, Do JY, Kim YH, Lee HY, Kim BS, Shin SK, Kim HC, Chang YK, Yang JO, Chung HC, Kim CD, Lee WK, Kim JY, Kim YL: Effects of neutral pH and low-glucose degradation product-containing peritoneal dialysis fluid on systemic markers of inflammation and endothelial dysfunction: a randomized controlled 1-year follow-up study. Nephrol Dial Transplant 2012;27:1191-1199.

29 Lai KN, Lam MF, Leung JC, Chan LY, Lam CW, Chan IH, Chan HW, Li CS, Wong SS, Ho YW, Cheuk A, Tong MK, Tang SC: A study of the clinical and biochemical profile of peritoneal dialysis fluid low in glucose degradation products. Perit Dial Int 2012;32:280-291.

-30 Johnson DW, Brown FG, Clarke M, Boudville N, Elias TJ, Foo MW, Jones B, Kulkarni H, Langham R, Ranganathan D, Schollum J, Suranyi M, Tan SH, Voss D, balANZ Trial Investigators: Effects of biocompatible versus standard fluid on peritoneal dialysis outcomes. J Am Soc Nephrol 2012;23:1097-1107.

-31 Takatori Y, Akagi S, Sugiyama H, Inoue J, Kojo S, Morinaga H, Nakao K, Wada J, Makino H: Icodextrin increases technique survival rate in peritoneal dialysis patients with diabetic nephropathy by improving body fluid management: a randomized controlled trial. Clin J Am Soc Nephrol 2011;6:1337-1344.

-32 Michels WM, Werduijn M, Grootendorst DC, Ie Cessie S, Boeschoten EW, Dekker FW, Krediet RT, NECOSAD study group: Decline in residual renal function in automated compared with continuous ambulatory peritoneal dialysis. Clin J Am Soc Nephrol 2011;6:537-542.

-33 Hiroshige K, Yuu K, Soejima M, Takasugi M, Kuroiwa A: Rapid decline of residual renal function in patients on automated peritoneal dialysis. Perit Dial Int 1996;16:307-315.

-34 De Fijter CW, Oe LP, Nauta JJ, van der MJ, Verbrugh HA, Verhoef J, Donker AJ: Clinical efficacy ad morbidity associated with continuous cyclic compared with continuous ambulatory peritoneal dialysis. Ann Intern Med 1994;120:264-271.

-35 Bro S, Bjorner JB, Tofte-Jensen P, Klem S, Almtoft B, Danielsen H, Meincke M, Friedberg M, Feldt-Rasmussen B: A prospective, randomized multicenter study comparing APD and CAPD treatment. Perit Dial Int 1999;19:526-533.

-36 Shemin D, Maaz D, St Pierre D, Kahn SI, Chazan JA: Effect of aminoglycoside use on residual renal function in peritoneal dialysis patients. Am J Kidney Dis 1999;34:14-20.

-37 Badve SV, Hawley CM, McDonald SP, Brown FG, Boudville NC, Wiggins KJ, Bannister KM, Johnson DW: Use of aminoglycosides for peritoneal dialysis-associated peritonitis does not affect residual renal function. Nephrol Dial Transplant 2012;27:381-387.

-38 Wang Q, Bernardini J, Piraino B, Fried L: Albumin at the start of peritoneal dialysis predicts the development of peritonitis. Am J Kidney Dis 2003;41:664-669.

-39 Medcalf JF, Harris KP, Walls J: Role of diuretics in the preservation of residual renal function in patients on continuous ambulatory peritoneal dialysis. Kidney Int 2001;59:1128-1133.

-40 Liao CT, Shiao CC, Huang JW, Hung KY, Chuang HF, Chen YM, Wu KD, Tsai TJ: Predictors of faster decline of residual renal function in Taiwanese peritoneal dialysis patients. Perit Dial Int 2008;28:S191-S195. 